\title{
Attitude, Social Norms, Perceived Behavioral Control, Past Behavior, and Habit in Explaining Intention to Consume Fish in Vietnam
}

HO HUY TUU

Nha Trang University - tuu_hohuy@yahoo.com

\section{ARTICLE INFO}

Article history:

Received:

Apr. 4. 2014

Received in revised form:

Apr. 28. 2015

Accepted:

Jun. 28. 2015

Keywords:

Fish, habit strength, past behavior, moderating effects.

\section{ABSTRACT}

The purpose of this study is to discuss and test the direct and moderating effects of attitudes, social norms, perceived behavioral control (PBC), past behavior, and habit strength in explaining Vietnamese consumers' intention to consume fish. In addition to a data set of 466 consumers in a coastal province in Central Vietnam and structural equation modelling, a model development strategy with six nested models is used to test hypotheses. Results indicate that attitude, social norms, and $\mathrm{PBC}$ have a positive effect on intention. Both past behavior and habit strength have a significantly positive influence on intention and considerably increase the explained variance of intention. In particular, the results also indicate that habit strength, past behavior, and social norms negatively moderate the impact of attitudes on intention. All of these findings emphasize the importance of past behavior and habit strength as well as interactions within the theory of planned behavior in explaining intention to consume fish in Vietnam. 


\section{Introduction}

Fish is the most common food in Vietnam, and having meals at home is the traditional characteristics of the families. Regardless of the increasing attraction of this market with the population of approximately ninety millions, very few studies we know explain motivations and behaviors toward eating fish (Cong et al., 2012; Tuu et al., 2008). This study seeks additional explanations for behavioral intention based on the theory of planned behavior (TPB) (Ajzen, 1991). In particular, it includes past behavior and habit (de Bruijin et al., 2007; Ouellette \& Wood, 1998) and explores potential interactions within the theoretical framework influencing intention to consume fish in this market.

The TPB (Ajzen, 1991) has been used widely in the identification of determinants of a wide range of behaviors (de Bruijin et al., 2007) including fish consumption (Olsen, 2001; Verbeke \& Vackier, 2005). The TPB proposes that behavioral intention is the function of attitudes, social norms, and perceived behavioral control (PBC). An important postulation of this theory posits the independence of those three constructs (Ajzen, 1991). However, theoretical discussions (Armitage \& Conner, 2001; Conner \& Armitage, 1998) and empirical evidence has challenged this postulation and proposed that social norms and PBC may interact with attitudes to influence on behavioral intention, for example, to use additive drugs (Conner \& McMillan, 1999; McMillan \& Conner, 2003; Umeh \& Patel, 2004). This study is conducted to provide additional evidence in the context of consuming such health food as fish.

Although using TPB in understanding human health behaviors is widely accepted (Armitage \& Conner, 2001), recent calls have been made to extend the TPB to include additional factors (Conner \& Armitage, 1998). Past behavior and habit strength have attracted a special interest of many researchers in different research areas (Cheng et al., 2005; de Bruijin et al., 2007; Trafimow, 2000; Verplanken \& Orbell, 2003). Several studies have also suggested that habit strength and past behavior may act as moderators within the TPB (de Bruijin et al., 2007; Norman et al., 2000; Norman \& Conner, 2006; Trafimow, 2000). Ajzen (1991) stressed that habit strength, if defined independently by the past behavior, would presumably capture the residues of past behavior that have established a habit or tendency to perform the behavior on future occasion. Habit strength and past behavior are, in addition, found to play an important role in the context of food choice (Saba et al., 2000; Verbeke \& Vackier, 2005). However, no 
studies we know refer to both habit strength and past behavior and simultaneously test the combined role in the theory of planned behavior. Therefore, this study contributes to the existing literature by addressing both past behavior and habit strength besides attitudes, social norms, perceived behavioral control, and accentuates their both direct and interaction effects on behavioral intention. If food consumption has habitual qualities, then this should have consequences for the persuasion strategies that are supposed to be used to influence people's eating habits (Honkanen et al., 2005). This study, which employs equation structural modelling to evaluate the reliability and valid of constructs and test proposed hypotheses, is thus expected to give not only a more pragmatic picture but also a deeper and more comprehensive understanding of behavioral intention to consume fish in Vietnam.

\section{Conceptual framework}

\subsection{The theory of planned behavior}

The TPB (Ajzen, 1991) is a cognitive model of human behavior, in which the central focus is the prediction and understanding of clearly defined behaviors. Intention can be regarded as a motivation to engage in a particular behavior and represents an individual's expectancies about his/her behavior in a given setting (Ajzen, 1991). In this study, intentional loyalty is defined as purchasing intentions as a probability to buy a product category. Intention is influenced by attitude, subjective norm, and perception of control over the behavior (Ajzen, 1991).

\subsection{Attitude}

Attitude is often defined as a psychological tendency that is expressed by evaluating a particular entity (e.g. fish) with some degree of favor-disfavor, like-dislike, satisfaction-dissatisfaction or good-bad polarity (Eagly \& Chaiken, 1993). Attitude is suggested to have a positive association with intention including seafood (Bredahl \& Grunert, 1997; Olsen, 2001; Tuu et al., 2008). Before further discussion, the following hypothesis is to be formulated:

\section{H1: Attitude has a positive effect on intentional loyalty}

However, the attitude-intention relationship is found to vary between products, industries, and situations, or may be affected by moderators (Visser et al., 2006). In 
this study, it is argued that social norms, PBC, past behavior, and habit strength may moderate the relationship.

\subsection{Social norms}

Social norms are normally supposed to capture the individual's perception being important to others in his or her social environment wish or expect him or her to behave in a certain way (Ajzen, 1991). In this study, social norms are defined as the approval of others' expectations, such as family norms (Olsen, 2001).

The findings within the literature are mixed, but most studies reported that social norms are an independent and important variable in explaining consumer intention (Ajzen, 1991). Social norms have been shown as an important factor in explaining the motivations toward eating fish in some studies (Cong et al., 2012; Olsen, 2001; Tuu et al., 2008; Verbeke \& Vackier, 2005). The viewpoint of social norms as a moderator in the attitude-intention relationship has been argued by Eagly and Chaiken (1993) that social pressure to enact a behavior has little impact if that behavior is viewed negatively, but increases intentions if the behavior is positively evaluated. They also argued that a positive attitude may facilitate a behavior only to the extent that significant others approve, but have little or no impact if there is a hostile social context. However, only few studies have tested the moderating effect of social norms on the attitude-intention relationship (Conner \& McMillan, 1999; McMillan \& Conner, 2003; Umeh \& Patel, 2004) and found a weak or insignificant effect. In food area Olsen (2001) proved that the effect of attitude on motivation decreases considerably when different aspects of social norms are included because of differences and conflicts between family members in consuming seafood. Based on the above discussions, the following hypothesis is proposed.

H2: Social norms: (a) have a positive effect on intention, and (b) negatively moderate the attitude-intention relationship.

\subsection{Perceived behavioral control (PBC)}

Ajzen (1991) focused on PBC as the person's beliefs as to how easy or difficult performance of the behavior is likely to be. The more resources and opportunities an individual thinks he or she possesses, the fewer obstacles or impediments they anticipate, and the greater should be their perceived control over the behavior. He also suggested that control factors can be either internal to the person (e.g. skills, abilities, 
power of will, and compulsion) or external to the person (e.g. time, opportunity, and dependence on others). $\mathrm{PBC}$ is defined in this study as an integrated measure of internal and external resources that make it easy to act upon the motivation to consume (Tuu et al., 2008).

Previous studies have proven that the inclusion of PBC improves the TPB model's ability to predict or explain intention (Armitage \& Conner, 2001; Verbeke \& Vackier, 2005). However, PBC fails to predict intention in quite many cases (Eagly \& Chaiken, 1993; McMillan \& Conner, 2003). Therefore, this study includes PBC together with attitudes and social norms, and expects that it has a positive effect on intention.

The role of $\mathrm{PBC}$ as a moderator in the attitude-intention relationship has been indicated in several studies of using additive drugs (Conner \& McMillan, 1999; Umeh $\&$ Patel, 2004). For example, Conner and McMillan (1999) reported that only when attitudes are neutral or negative should PBC predict intentions negatively, and in contrast, when attitudes are positive, $\mathrm{PBC}$ is no longer significant. This interaction can also be viewed from the perspective of attitude that positive evaluations may instigate or have no effect on a behavior given strong and weak perceptions of control, respectively (Umeh \& Patel, 2004). The next hypothesis is thus proposed:

H3: Perceived behavioral control: (a) has a positive effect on intention, and (b) negatively moderates the attitude-intention relationship.

\subsection{Habit strength and past behavior}

Triandis (1980) defines habit as “... situation-behavior sequences that are or have become automatic, so that they occur without self-instruction" (p. 204). Verplanken and Aarts (1999) referred to habits as "... learned sequences of acts that have become automatic responses to specific cues, and are functional in obtaining certain goals or end states" (p. 104). A major problem is the way habit has been conceptualized and measured, whereby habit is usually measured as repetition as past behavioral frequency (Cheng et al., 2005; Ouellette \& Wood, 1998). However, repetition is only a necessary condition to develop a habit, and habit should be distinguished from behavioral frequency (Honkanen et al., 2005). Because it cannot be assumed that past behavior is a valid measure for habitual behavior, only when habit is defined independently of past behavior can it legitimately be added as an explanatory variable to the TPB (Ajzen, 1991). In addition, Wood et al. (2005) explained habit as the cognitive, neurological, and motivational changes that occur when behavior is repeated. Therefore, in this 
study, habit or habit strength is defined as automatic or unconscious responses (e.g. lack of awareness, lack of control, and lack of mental efficiency) to behave to future behaviors and as the leaned consequences of repetition (Honkanen et al., 2005; Verplanken \& Aarts, 1999).

Eagly and Chaiken (1993) and Ajzen (2000) both acknowledged the role of habit strength and past behavior within the TPB that the salience of TPB constructs, including potential interactions, may be attenuated somewhat when juxtaposed against these background variables, especially habit strength and past behavior (Ajzen, 2000; Eagly, \& Chaiken, 1993).

Habit strength has been shown to impact on intention, irrespective of TPB variables (Brug et al., 2006; Conner \& McMillan, 1999; Honkanen et al., 2005; Verbeker \& Vackier, 2005). The suggestion for the moderating effect of habit strength in the attitude-intention relationship is based on the fact that the automaticity of behavior lessens the need to access intention (Aarts et al., 1997). This means that people who have well-developed intentions (i.e. they base their intentions on their attitude) will show a relatively strong relationship between attitude and intention; by contrast, those who do not have well-developed intentions may use their habit as a basis for their response (Honkanen et al., 2005). Furthermore, if a person is in the habit of performing a behavior, there would seem to be no need to perform the reasoning assumed by the theory of reasoned action (Aarts et al., 1998), and the predictive power of attitude should be attenuated (Trafimow, 2000). Contrarily, when people are not in the habit of performing a behavior, the attitude should well predict intentions. In addition, most previous studies have found that the attitude-intention relationship is typically weaker when the behavior is habitual than when the behavior is not habitual (de Bruijin et al., 2007; Honkanen et al., 2005; Knussen et al., 2004). The above discussions accordingly enable the following hypothesis to be suggested:

H4: Habit strength: (a) has a positive effect on intention, and (b) negatively moderates the attitude-intention relationship.

Similarly, the habit literature maintained that the best predictor of behavioral intention is the frequency of a past behavior (Eagly \& Chaiken, 1993; Ouellette \& Wood, 1998), and that past behavior may predict intention independently of TPB variables (Cheng et al., 2005; Honkenen et al., 2005; Ouellette \& Wood, 1998). The inclusion of past behavior can explain the variance of intention more than attitude, 
social norms, and PBC can (Norman et al., 2000; Ouellette \& Wood, 1998; Verbeker \& Vackier, 2005). In addition, Verplanken et al. (1997) proposed that repeatedly performing a behavior will lead to a reduction in the amount of deliberative processing. Therefore, the importance of attitude in determining intention decreases as the frequency of past behavior increases (Norman et al., 2000). Since some evidence has backed up the negative moderating effect of past behavior on the attitude-intention relationship (Norman \& Conner, 2006; Ouellette \& Wood, 1998), another hypothesis can be as follows:

H5: Past behavior: (a) has a positive effect on intention, and (b) negatively moderates the attitude-intention relationship.

As a summary, this study is based on the TPB (Ajzen, 1991) with some justifications. Firstly, it includes the moderating effects of social norms (Conner \& McMillan, 1999; McMillan \& Conner, 2003) and perceived behavioral control (Conner \& McMillan, 1999; Umeh \& Patel, 2004) on the attitude-intention relationship. Secondly, it extends to combine both habit strength and past behavior in the model (Cheng et al., 2005; de Bruijin et al., 2007; Honkanen et al., 2005; Knussen et al., 2004; Norman et al., 2000; Ouellette \& Wood, 1998; Verbeker \& Vackier, 2005). Based on the proposed hypotheses, the theoretical model is given in Figure 1.

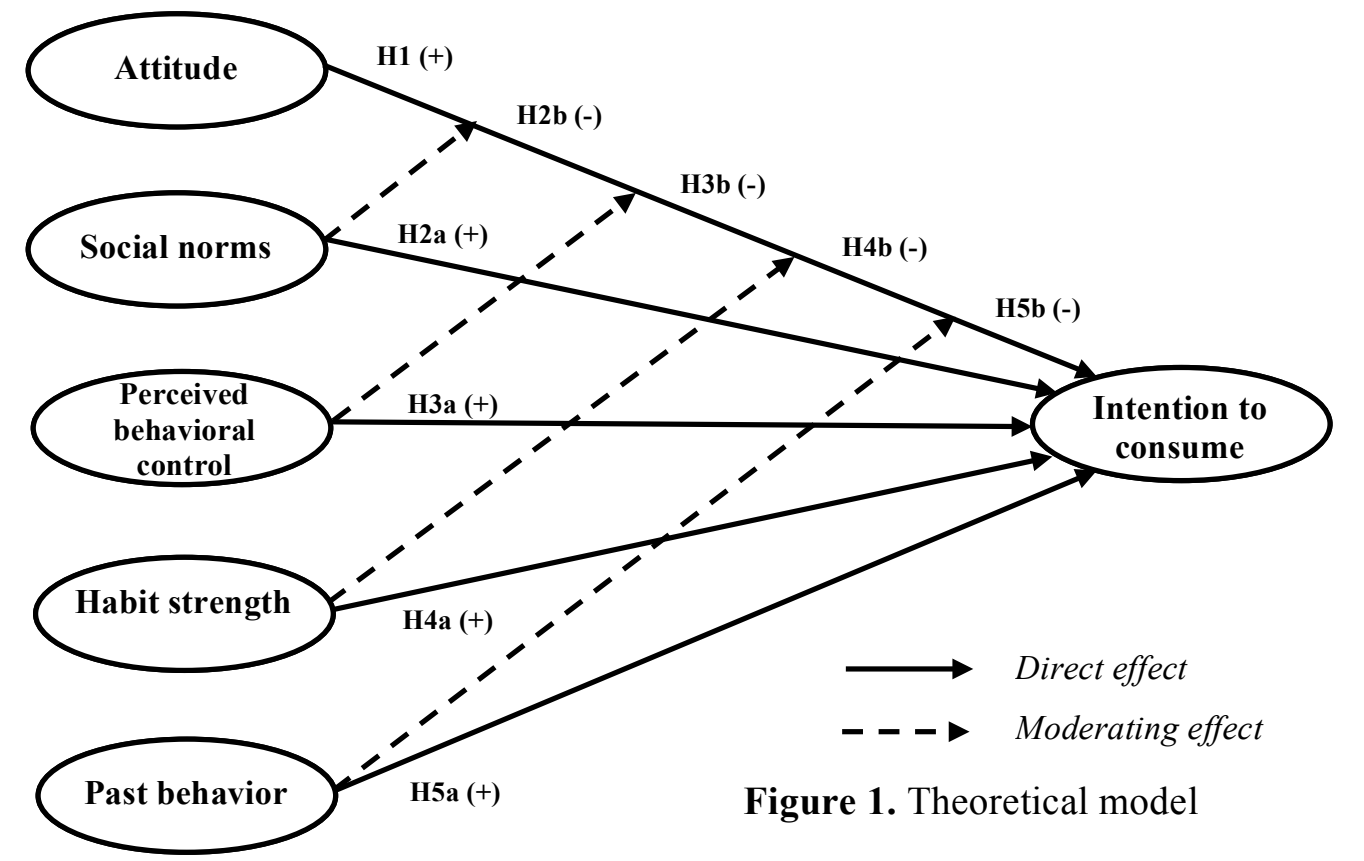




\section{Research methodology}

\subsection{Products and respondents}

Fish is a mainstay of Vietnamese diets, ensuring a high incidence rate of familiarity with the product. A sample of 466 respondents aged from 18 was gathered from three locations (Nha Trang, Dien Khanh, and Cam Ranh) in a coastal province (Khanh Hoa) in Central Vietnam. Households were interviewed door-to-door, and the person responsible for preparing meals for their family answered the questionnaire. Respondents were also clearly informed that this study would only focus on fish as a product category. The typical respondents are female $(72.5 \%)$, married $(73.4 \%)$, educated within 15 years $(78.5 \%)$, and are 44 years of age (range 18-76 years).

\subsection{Measurements}

Intention to consume is assessed by a 7-point scale consisting of three items, indicating how likely the subjects "intend", "want", and "are willing to" to buy and eat fish as a meal during the three coming days, coded from Totally unlikely (1) to Totally likely (7) (Tuu et al., 2008).

Attitude is measured by three statements of attitude evaluation and fish preferences on a 7-point bipolar scale as follows: "When I eat fish as the everyday main meal, I feel": Unsatisfied (1) to Satisfied (7), Unpleasant (1) to Pleasant (7); and Disliking (1) to Liking (7). These items cover general positive feeling statements often used to assess attitudes towards food-objects and/or food behavior (Shepherd \& Raats, 1996).

Social norms construct is addressed to include only the family as a reference group (Olsen, 2001) and measured by three statements: "My family encourage me to eat fish regularly", "My family want me to eat fish regularly", and "My family think that I should eat fish regularly" on a 7-point Likert-scale anchored by disagree strongly (-3), neither disagree nor agree $(0)$, and agree strongly $(+3)$. 


\section{Table 1}

Descriptive statistics of indicators

\begin{tabular}{|c|c|c|c|c|c|c|}
\hline \multirow[b]{2}{*}{ Constructs and indicators } & \multirow[b]{2}{*}{ Mean } & \multirow{2}{*}{$\begin{array}{l}\text { Std. } \\
\text { Error }\end{array}$} & \multicolumn{2}{|c|}{ Skewness } & \multicolumn{2}{|c|}{ Kurtosis } \\
\hline & & & Value & $\begin{array}{l}\text { Std. } \\
\text { Error }\end{array}$ & Value & $\begin{array}{l}\text { Std. } \\
\text { Error }\end{array}$ \\
\hline \multicolumn{7}{|l|}{ Intention to consume } \\
\hline I have intention to buy and eat fish & 5.46 & 1.65 & -0.73 & 0.11 & -0.42 & 0.22 \\
\hline I want to buy and eat fish & 5.32 & 1.70 & -0.81 & 0.11 & -0.26 & 0.22 \\
\hline I am willing to buy and eat fish & 5.45 & 1.74 & -0.85 & 0.11 & -0.18 & 0.22 \\
\hline \multicolumn{7}{|l|}{ Attitude } \\
\hline Unpleasant/Pleasant & 5.13 & 1.57 & -0.96 & 0.11 & 0.28 & 0.22 \\
\hline Unsatisfied/Satisfied & 5.12 & 1.62 & -0.99 & 0.11 & 0.31 & 0.22 \\
\hline Disliking/Liking & 5.02 & 1.67 & -0.78 & 0.11 & -0.09 & 0.22 \\
\hline \multicolumn{7}{|l|}{ Social norms } \\
\hline Family want me ... & 5.23 & 1.52 & -0.94 & 0.11 & 0.47 & 0.22 \\
\hline Family encourage me ... & 5.21 & 1.50 & -0.92 & 0.11 & 0.49 & 0.22 \\
\hline Family think that I should... & 5.24 & 1.49 & -0.98 & 0.11 & 0.71 & 0.22 \\
\hline \multicolumn{7}{|l|}{ Perceived behavioral control (PBC) } \\
\hline It is first and almost up to myself ... & 5.74 & 1.46 & -0.75 & 0.11 & 0.11 & 0.22 \\
\hline It is entirely up to me to what ... & 5.70 & 1.33 & -0.81 & 0.11 & 0.88 & 0.22 \\
\hline It is within my principles to eat ... & 5.81 & 1.25 & -0.91 & 0.11 & 0.68 & 0.22 \\
\hline \multicolumn{7}{|l|}{ Habit strength } \\
\hline I do without much thinking ... & 5.15 & 1.57 & -0.87 & 0.11 & 0.14 & 0.22 \\
\hline I do without any plan... & 4.54 & 1.84 & -0.49 & 0.11 & -0.78 & 0.22 \\
\hline I do without having consciously... & 4.50 & 1.87 & -0.37 & 0.11 & -0.94 & 0.22 \\
\hline \multicolumn{7}{|l|}{ Past behavior } \\
\hline Consumption frequency & 3.89 & 1.62 & 0.42 & 0.11 & -0.58 & 0.22 \\
\hline
\end{tabular}

Source: Investigated by the author; $\mathrm{n}=466$.

Perceived behavioral control is measured by three items on the same 7-point Likertscale in the forms: "It is first and almost up to myself whether or not I eat fish", "It is entirely up to me to what extent I will eat fish or not", and "It is within my principles 
to eat fish". These items are frequently used to assess the perceived behavioral control within consumer and/or social psychology including food behavior (Verbeker \& Vackier, 2005).

Habit strength is measured by three items of the self-report index of habit strength scale (Verplanken \& Orbell, 2003). The above 7-point Likert-scale is used starting with the stem: "Eating fish for me is something: I do without much thinking about doing it; I do without any plan; I do without having consciously remembered about having done". These three items represent the facets of lack of awareness, lack of control, and mental efficiency of the habit (Honkanen et al., 2005).

The measure of past behavior uses a one-year time frame and is addressed by a 7point scale of the form, "How many times on average during the last year have you eaten fish as a meal?" $(1=1-2$ times a week, $2=3-4$ times a week, $3=4-5$ times a week, etc., up to $7=$ more 12 times a week). The variance of this scale is fixed to 0 . This measure is adapted from previous studies assessing food consumption frequency (Cong et al., 2012; Tuu et al., 2008).

A summary of the data is shown in Table 1. All absolute values of Skewness and Kurtosis are less than 1.00, which reveals that the distributions of all indicators are approximately normal. This result is appropriate to further analyses.

\subsection{Analytical procedure}

In this study a SEM approach is used to validate the intended constructs and to estimate the proposed theoretical model (Anderson \& Gerbing, 1988). A key contribution of the SEM is to link and investigate the relationship between latent variables and observable variables. This approach consists of two different models: (i) measurement model, which is used to link observable indicators to the latent variables (e.g. habit strength), and (ii) a structural equation model, which is used to present the relationship between causes and consequences among various latent variables (e.g. habit strength and intention). This approach has been adopted more commonly in recent years in Vietnam (see Vo \& Ly, 2014 for more discussions).

First, the study assesses the intended constructs to ensure the internal consistency and the convergent and discriminant validity of the constructs (Anderson \& Gerbing, 1988) by performing a confirmatory factor analysis using AMOS. Second, it tests the hypotheses using the two-step estimation approach developed by Ping (1995) for 
modelling latent variable interactions. This approach overcomes the limitations of other alternatives, such as indicant product analysis (Kenny \& Judd, 1984), which can be tedious to use (Ping, 1995), subgroup analysis, which can lead to a reduction of statistical power (Jaccard et al., 1990), or multivariate regression, which does not account for measurement errors (Aiken \& West, 1991). Furthermore, Cortina et al. (2001) have shown that this approach generates results totally similar to those estimated by different procedures in SEM for testing moderators (see Cortina et al., 2001 for a review), but conceptually and operationally, it is more straightforward.

\section{Results}

\subsection{Reliability and validity of the measures}

A confirmatory factor analysis (CFA) of the measurement model including six constructs in the theoretical model as in Figure 1 results in a good fit with the data $\left(\chi^{2}\right.$ $=220.0 ; d f=90, p<0.000 ; \mathrm{RMSEA}=0.06 ; \mathrm{GFI}=0.94$; and $\mathrm{CFI}=0.97)($ Browne $\&$ Cudeck, 1992).

As shown in Table 2, all factor loadings on the constructs are highly significant ( $p<$ 0.001: $t$-value $>12.0$ ) with values ranging from 0.59 to 0.95 , which shows the convergent validity of the constructs. The composite reliabilities exceed the minimum value of 0.70 , and the variances extracted surpass the recommended threshold of 0.50 (Anderson \& Gerbing, 1988).

\section{Table 2}

Constructs and indicators

\begin{tabular}{|c|c|c|c|c|}
\hline Constructs and indicators & $\begin{array}{l}\text { Factor } \\
\text { loadings }\end{array}$ & t-values & $\begin{array}{c}\text { Composite } \\
\text { reliability }\end{array}$ & $\begin{array}{c}\text { Extracted } \\
\text { variance }\end{array}$ \\
\hline Intention to consume & & & 0.89 & 0.74 \\
\hline I have intention to buy and eat fish & 0.86 & 22.5 & & \\
\hline I want to buy and eat fish & 0.89 & 23.8 & & \\
\hline I am willing to buy and eat fish & 0.83 & 21.2 & & \\
\hline Attitude & & & 0.90 & 0.75 \\
\hline Unpleasant/Pleasant & 0.92 & 25.0 & & \\
\hline Unsatisfied/Satisfied & 0.92 & 25.1 & & \\
\hline
\end{tabular}




\begin{tabular}{|c|c|c|c|c|}
\hline Constructs and indicators & $\begin{array}{l}\text { Factor } \\
\text { loadings }\end{array}$ & t-values & $\begin{array}{l}\text { Composite } \\
\text { reliability }\end{array}$ & $\begin{array}{l}\text { Extracted } \\
\text { variance }\end{array}$ \\
\hline Intention to consume & & & 0.89 & 0.74 \\
\hline Disliking/Liking & 0.74 & 18.1 & & \\
\hline Social norms & & & 0.94 & 0.83 \\
\hline Family want me to... & 0.90 & 24.6 & & \\
\hline Family encourage me to ... & 0.95 & 26.9 & & \\
\hline Family think that I should... & 0.89 & 24.2 & & \\
\hline Perceived behavioral control (PBC) & & & 0.82 & 0.60 \\
\hline It is first and almost up to myself whether ... & 0.59 & 13.0 & & \\
\hline It is entirely up to me to what extent $\ldots$ & 0.89 & 20.4 & & \\
\hline It is within my principles to eat fish & 0.82 & 18.7 & & \\
\hline Habit strength & & & 0.86 & 0.67 \\
\hline I do without much thinking about eating it & 0.81 & 19.6 & & \\
\hline I do without any plan & 0.84 & 20.7 & & \\
\hline I do without having consciously remember ... & 0.80 & 19.3 & & \\
\hline Past behavior (fixed) & 1.00 & 30.5 & - & - \\
\hline
\end{tabular}

Note: All factor loadings are significant at $\mathrm{p}<0.001$

As shown in Table 3, all the correlations do not exceed 0.50, and the squared correlation between each of the constructs (the highest value at 0.22 ) is less than the average variance extracted from each pair of constructs (the lowest value at 0.60), which constitutes discriminant validity (Fornell \& Lacker, 1981).

\section{Table 3}

Construct means, standard deviations, and correlations

\begin{tabular}{lccccccc}
\hline & Mean & Std. & 1 & 2 & 3 & 4 & 5 \\
\hline 1. Attitude & 5.09 & 1.46 & - & & & \\
2. Social norms & 5.22 & 1.40 & $0.06^{\text {ns }}$ & - & & \\
3. PBC & 5.75 & 1.22 & 0.13 & 0.17 & - & \\
4. Habit & 4.73 & 1.62 & $-0.03^{\text {ns }}$ & 0.18 & 0.14 & -
\end{tabular}




\begin{tabular}{lccccccc}
\hline & Mean & Std. & 1 & 2 & 3 & 4 & 5 \\
\hline 5. Past behavior & 3.89 & 1.62 & 0.15 & $0.04^{\text {ns }}$ & $0.04^{\text {ns }}$ & 0.25 & - \\
6. Intention & 5.41 & 1.42 & 0.46 & 0.20 & 0.22 & 0.25 & 0.47 \\
\hline
\end{tabular}

Note: ${ }^{\text {ns }}$ : insignificant

\subsection{Testing direct effects}

\section{Table 4}

Predicting intention to consume fish

\begin{tabular}{|c|c|c|c|c|c|c|c|}
\hline $\begin{array}{c}\text { Step } \\
\text { Variables } \\
\text { Hypotheses }\end{array}$ & & $\begin{array}{c}\text { Step 1: } \\
\text { Coefficient } \\
\text { (t-value) }\end{array}$ & $\begin{array}{c}\text { Step 2: } \\
\text { Coefficient } \\
\text { (t-value) }\end{array}$ & $\begin{array}{c}\text { Step 3: } \\
\text { Coefficient } \\
\text { (t-value) }\end{array}$ & $\begin{array}{c}\text { Step 4: } \\
\text { Coefficient } \\
\text { (t-value) }\end{array}$ & $\begin{array}{c}\text { Step 5: } \\
\text { Coefficient } \\
\text { (t-value) }\end{array}$ & $\begin{array}{c}\text { Step 6: } \\
\text { Coefficient } \\
\text { (t-value) }\end{array}$ \\
\hline 1. Attitude & $\mathrm{H} 1$ & $0.43 * * *(8.4)$ & $0.38 * * *(8.2)$ & $0.38 * * *(8.4)$ & $0.38 * * *(8.4)$ & $0.42 * * *(9.4)$ & $0.42 * * *(9.6)$ \\
\hline Social norms & $\mathrm{H} 2 \mathrm{a}$ & $0.16^{* * *}(3.6)$ & $0.13 * *(3.1)$ & $0.13 * *(3.2)$ & $0.13 * *(3.2)$ & $0.12 * *(3.0)$ & $0.12 * *(3.1)$ \\
\hline PBC & $\mathrm{H} 3 \mathrm{a}$ & $0.13 * *(2.8)$ & $0.11 * *(2.6)$ & $0.11 * *(2.7)$ & $0.11 * *(2.6)$ & $0.08^{\mathrm{ns}}(1.9)$ & $0.09 *(2.3)$ \\
\hline 2. Habit strength & $\mathrm{H} 4 \mathrm{a}$ & - & $0.13 * *(3.0)$ & $0.13 * *(2.8)$ & $0.12 * *(2.8)$ & $0.15 * * *(3.5)$ & $0.11 * *(2.6)$ \\
\hline Past behavior & $\mathrm{H} 5 \mathrm{a}$ & - & $0.37 * * *(8.8)$ & $0.37 * * *(8.8)$ & $0.37 * * *(8.8)$ & $0.30 * * *(7.2)$ & $0.29 * * *(7.3)$ \\
\hline 3. Attitude*Norms & $\mathrm{H} 2 \mathrm{~b}$ & - & - & $-0.14 * * *(-3.6)$ & $-0.14 * * *(-3.5)$ & $-0.09 *(-2.3)$ & $-0.09 *(-2.5)$ \\
\hline 4. Attitude*PBC ${ }^{2}$ & $\mathrm{H} 3 \mathrm{~b}$ & - & - & - & $-0.00^{\mathrm{ns}}(-0.1)$ & $0.05^{\mathrm{ns}}(1.2)$ & $0.05^{\mathrm{ns}}(1.2)$ \\
\hline 5. Attitude*Habit ${ }^{2}$ & $\mathrm{H} 4 \mathrm{~b}$ & - & - & - & - & $-0.27 * * *(-6.1)$ & $-0.19 * * *(-3.8)$ \\
\hline 6. Atti*P.behavior ${ }^{2}$ & $\mathrm{H} 5 \mathrm{~b}$ & - & - & - & - & - & $-0.19 * * *(-4.0)$ \\
\hline $\mathrm{R}^{2}$ intention (\%) & & 25.1 & 42.2 & 44.1 & 44.1 & 51.2 & 54.2 \\
\hline Chi-square (df) & & $97.5(49)$ & $187.9(94)$ & $305.5(141)$ & $472.5(194)$ & $667.0(255)$ & $779.5(326)$ \\
\hline$P$ & & 0.000 & 0.000 & 0.000 & 0.000 & 0.000 & 0.000 \\
\hline GFI & & 0.97 & 0.95 & 0.94 & 0.91 & 0.90 & 0.89 \\
\hline CFI & & 0.99 & 0.98 & 0.97 & 0.96 & 0.95 & 0.95 \\
\hline RMSEA & & 0.05 & 0.05 & 0.05 & 0.06 & 0.06 & 0.06 \\
\hline
\end{tabular}

Note: $* \mathrm{p}<0.05 ; * * \mathrm{p}<0.01 ; * * * \mathrm{p}<0.001$; ns: insignificant. 
A hierarchical regression analysis using structural equation modeling is used to test the proposed hypotheses. For testing the direct effects, the independent variables are entered into the two steps. The step 1 includes attitude, social norms, and PBC. At the step 2, both habit strength and past behavior are added. The results indicate the acceptable fits of the models (GFI $=0.89-0.97$; CFI $=0.95-0.99$; RMSEA $=0.05-0.06$ ). The standardized coefficients, $t$-values, and fit statistics are shown in the above Table 3.

The results supports the hypotheses $1,2 \mathrm{a}$, and $3 \mathrm{a}$ that attitude $(\mathrm{H} 1: \beta=0.38-0.43 ; \mathrm{t}=$ 8.2-8.4; $p<0.001$ ), social norms (H2a: $\beta=0.12-0.16$; $\mathrm{t}=3.0-3.6 ; p<0.01$ ), and PBC (H3a: $\beta=0.08-0.13, \mathrm{t}=1.9-2.8 ; p<0.05$ ) have a direct positive effect on intention to consume. Attitude, social norms, and PBC explain $25.1 \%$ of the variance in intention.

Next, habit strength (H4a: $\beta=0.11-0.15 ; \mathrm{t}=2.6-3.5 ; p<0.01$ ) and past behavior (H5a: $\beta=0.29-0.37 ; \mathrm{t}=7.2-8.8 ; p<0.001)$ have proven to be important predictors for intention. The addition of habit strength and past behavior substantially leads to an increase in the amount of variance explained in intention by $17.1 \%(42.2 \%-25.1 \%=17.1 \%)$.

\subsection{Testing moderating effects}

Testing the moderating effects is based on indicant product analysis (Kenny \& Judd, 1984) by multiplying the items of two interacted constructs to generate the indicators of the interacting term between them. Then, those indicators are grouped into three composite items by averaging arbitrarily among those indicators (Joreskog \& Sorbom, 1982). In addition, before indicant products are generated, all the constructs are changed in the origins of scales by mean-centering to reduce the correlations between the involved constructs and their interactions (Aiken \& West, 1991). Finally, the interaction terms are entered into the hierarchical regression analyses from the step 3 to the step 6 .

The results in Table 4 indicate that the interaction between attitude and PBC has no effect on intention (H3b: $\beta=0.00$ to $-0.05 ; \mathrm{t}=-0.1$ to $-1.2 ; p>0.05$ ), implying that Hypothesis $\mathrm{H} 3 \mathrm{~b}$ is not supported. However, the hypotheses $\mathrm{H} 2 \mathrm{~b}, \mathrm{H} 4 \mathrm{~b}$, and H6b are supported. The interaction between attitude and social norms has a significantly negative effect (H3b: $\beta=-0.09$ to $-0.14 ; \mathrm{t}=-2.3$ to $-3.6 ; p<0.05$ ) on intention. This means that the attitude-intention relationship becomes weaker as consumers perceive higher social norms. The inclusion of this interacting effect increases the variance of intention by $1.9 \%$ (step 3 : $44.1 \%-42.2 \%=1.9 \%)$. 
Also in Table 4 at the step 5 and the step 6, when the interactions of attitude by habit strength, and attitude by past behavior are added to the analysis, the variance in intention increases considerably by $7.1 \%(51.2 \%-44.1 \%=7.1 \%)$ and $3.0 \%(54.2 \%-51.2 \%=$ $3.0 \%$ ), respectively. These increases in the explained variance of intention are due to the significant interaction effects of attitude by habit strength $(\mathrm{H} 4 \mathrm{~b}: \beta=-0.19$ to $-0.27 ; \mathrm{t}=-3.8$ to $-6.1 ; p<0.001$ ), and of attitude by past behavior (H5b: $\beta=-0.19 ; \mathrm{t}=-4.0 ; p<0.001$, respectively) on intention. Therefore, the results support the hypotheses $\mathrm{H} 4 \mathrm{~b}$ and $\mathrm{H} 5 \mathrm{~b}$.

\section{Discussions}

The purpose of this study is to extend the theory of planned behavior by including habit strength and past behavior as well as to examine interaction effects to explain the intention to consume fish in Vietnam. The analyses are based on a survey data and structural structure modelling to test the hypotheses, using hierarchical models. The findings support most the proposed hypotheses; therefore, this study generates some contributions in both academic and practical fields.

Consumers' attitude is the most important predictor of intention to consume fish in the research sample. The average mean of the attitude score is high (5.09 on a scale from 1 to 7) indicating a significantly positive attitude toward fish in this sample. This result supports earlier studies suggesting that attitudes are the most important antecedent of intention in the TPB (Conner \& Armitage, 2001; Norman \& Conner, 2006). Additional support for the result is also suggested in the studies of fish and seafood in Norway (Honkanen et al., 2005; Olsen, 2001), and Belgium (Verbeke \& Vackier, 2005). However, this outcome differs from theirs' in that the magnitude of the attitude-intention relationship is much weaker than those of past behavior-intention and habit-intention relationships.

Social norms fail to predict intention in 10 out of 19 investigations summarized by Ajzen (1991). The present study, with a measure focusing on family wants and expectations, confirms a significant relationship between social norm and intention to consume fish (Cong et al., 2012; Olsen, 2001). The tradition of having a shared meal in most Vietnamese households gives reasons for the "housewife" not only to listen to her family, but to take them seriously and incorporate their attitudes into her motivational aspect (Tuu et al., 2008). However, the exploratory power of social norms on intention is weaker than attitude, which is consistent with the studies on intention to eat health food (Conner et al., 2002), seafood/fish (Verbeke \& Vackier, 2005) and several other behaviors 
(Armitage \& Conner, 2001). Interestingly, this study finds that social norms still interact with attitude to affect intention. Although Umeh and Patel (2004) included an interaction between attitude and social norms to explain intention to use cannabis, they failed to indicate a significant interaction effect. Thus, this study is the first to provide empirical evidence support for the moderator role of social norms in the attitude-intention framework. In fact, the result is based on reference differences and conflicts between family members in consuming fish, which cause the vulnerability in the housewife's attitude, and they also have to make decisions in choosing foods to fulfill the pleasure of all members in the family (Cong et al., 2012; Olsen, 2001). Therefore, consuming fish in the Vietnamese families may be a reconciling process.

Further consistency with the TPB (Ajzen, 1991) is that the inclusion of perceived behavioral control may have an independent effect on intention after controlling for attitude and social norms (Armitage \& Conner, 2001; Notani, 1998). However, PBC is found as the weakest predictor of intention to consume fish when the aspects of habit are covered (Verbeke \& Vacackier, 2005). The reasons may be that the motivation to consume fish is under volitional control, or in other words, the consumers' intention to eat fish is driven significantly by their general attitude and family expectations over fish consumption. This is also consistent with the discussions by Ajzen (1991) that in certain situations where attitude is strong, or where normative influences are powerful, PBC may be less predictive of intention. These reasons may also help to explain why PBC does not interact significantly with attitude to affect intention to consume fish in this study.

Furthermore, previous studies on consuming fish have suggested that the inclusion of habit strength helps increase the explained variance in behavioral intention (Honkanen et al., 2005; Saba et al., 2000; Verbeke \& Vackier, 2005). This study finds a significantly positive effect of habit strength on intention, but the magnitude of habit effect is much weaker than attitude. So frequently does the consumption of fish occur in the present context that it is supposed that consumers' intention may be formed partly based on habit, but it does not necessarily mean that no reason precedes their intentions. Astoundingly, this study finds a strongly negative moderating effect of habit strength on the attitude-intention relationship, thereby being compatible with previous studies (de Bruijin et al., 2007; Honkanen et al., 2005; Knussen et al., 2004; Trafimow, 2000). This means that consumers manage to reduce cognitive efforts involving frequent decisions of buying fish by development of habit as a shortcut; thus, the predictive power of attitude on intention is attenuated (Trafimow, 2000). Because attitude has a significantly positive effect on 
intention, the forming of intention to consume fish in the market may or may not have reasons, even with the presence of habit strength. Such result is consistent with the viewpoints of Verbeke and Vackier (2005) in the consumption of fish in Belgium, but inconsistent with those of Trafimow (2000), who have proposed that "reasoned" processes may only be valid for people who do not habitually perform the behavior of concern. It is likely that the diversity of food categories and the possible food risks (Tuu \& Olsen, 2009) in this market are factors making housewives more difficult in choosing fish.

Consistent with that suggested in previous studies, past behavior has proven to be a strong predictor to intention (Cheng et al., 2005; Ouellette \& Wood, 1998). More importantly, past behavior, however, is found to negatively moderate the attitude-intention relationship, which is consistent with most previous studies (Normann et al., 2000; Norman \& Conner, 2006) and supports the idea that repeatedly performing a behavior leads to a reduction in the amount of deliberative processing (Verplanken et al., 1997). As a consequence, there is a reduction in the importance of attitudes in determining intentions as the frequency of past behavior increases (Norman \& Conner, 2006). In comparison with habit strength, the role of past behavior is almost the same in this study, which may indicate that people with strong habits base their expression of intentions on a reflection of their past behavior (Honkanen et al., 2005).

In sum, these findings are intriguing because they support the viewpoint of using frequency of past behavior as a measure of habit strength (Triandis, 1980), especially in the context of behaviors occurring frequently and in a stable environment (Ouellette \& Wood, 1998), like eating fish. Thus, the findings should well fulfill the calls for developing and comparing alternative measures of habit in order to assess the direct effect of habitual processes on intentions and behaviors as well as the moderating role of habitual aspects in relation to the TPB framework (Norman \& Conner, 2006).

\section{Conclusion, implications, and limitations}

This study is the first in Vietnam to include both habit strength and past behavior as well as to examine interactions between TPB variables affecting intention at least in food marketing and consumer behavior areas. The findings have two important implications:

Firstly, the role of TPB variables in explaining intention to consume fish in Vietnamese fish market seems more complex than is previously thought, especially the role of social norms. These findings support the criticism of ignorance of important interactions between 
the proximal determinants of behavioral intentions (Eagly \& Chaiken, 1993; Norman \& Conner, 2006). Attention should focus on the context of Vietnamese families, where closed relations between family members strongly affect the forming of consumers' motivations.

Secondly, understanding the theoretical bases of habit aspects is important to practitioners who wish to maintain or change behavior or behavioral intentions including eating habits (Honkanen et al., 2005). The presence of the strong habit of eating fish as healthy food is a good news for fish companies, but communication campaigns should be carried out to consolidate the positive attitude toward fish as the strongest predictor for motivation to eat fish in this market. More specifically, communication campaigns which focus on weak habit segments may be more efficient. Generally, from theoretical as well as practical perspectives, habit aspects are an important factor to be considered in the food domain (Honkanen et al., 2005).

However, some limitations should be noticed. The present research is based on a convenience sample from the single province in Central Vietnam, so the results cannot represent the whole of population. Future study should expand to a more representative sample in Vietnam and to other food products. Next, the study has not measured actual behavior; thus, the gap between intention and future behavior is problematic in inference, and a longitudinal design is encouraged. Furthermore, additional variables (e.g. moral norms, self-identity, and so on) could also be discussed (Conner \& Armitage, 1998). The results presented here are based on cross-sectional data, and the measures utilized in this study have been self-reported; hence, causal effects cannot actually be inferred. Experimental designs should be employed in order to meet the issues of causality in the future studies

\section{Notes}

${ }^{1}$ This analysis was conducted with the use of maximum-likelihood estimation. The traditional chi square fit test is reported. However, because it has been recognized as an inappropriate test for large sample size, three other indices are also included: root mean-square error of approximation (RMSEA), goodness of fit index (GFI), and comparative-fit index (CFI). Acceptable model fits are indicated by GFI and CFI values exceeding 0.90, and RMSEA values below 0.08 (Browne \& Cudeck, 1992).

2 The significance of an interaction effect indicates a moderator. For example, at the step 3, the interaction between attitude and norms has a significantly negative effect on intention $(\beta=-0.14 ; \mathrm{t}=-3.6$; 
$\mathrm{p}<0.001$ ). This means that when norms increases by one unit, the magnitude of the relationship between attitude and intention decreases by 0.14 .

\section{References}

Aarts, H., Paulussen, T., Willemse, C., Schaalma, H., Bolman, C., \& de Nooyer, J. (1997). Prevention of cardiovascular diseases: A review of international studies on the promotion of physical activity among youth. The Hague/Woerden/ Maastricht: Dutch Heart Foundation, NIGZ, Maastricht University.

Aarts, H., Verplanken, B., \& van Knippenberg, A. (1998). Predicting behavior from actions in the past: Repeated decision making or a matter of habit? Journal of Applied Social Psychology, 28, 13551374.

Aiken, L. S., \& West, S. G. (1991). Multiple regression: Testing and interpreting interactions. Thousand Oaks, CA: Sage.

Ajzen, I. (1991). The theory of planned behavior. Organizational behavior and human decision process, 50, 179-211.

Anderson, J. C., \& Gerbing, D. W. (1988). Structural equation modelling in practice: A review and recommended two step approach. Psychological Bulletin, 103, 411-423.

Armitage, C., \& Conner, M. (2001). Meta-analysis of the theory of planned behaviour. British Journal of Social Psychology, 40, 471-499.

Bredahl, L., \& Grunert, K. G. (1997). Determinants of the consumption of fish and shellfish in Denmark: An application of the theory of planned behavior. In J. B. Luten, T. Børresen \& J. Oehlenschla"ger (eds.), Seafood from producer to consumer, integrated approach to quality (pp. 21-30). Amsterdam: Elsevier.

Browne, M. W., \& Cudeck, R. (1992). Alternative ways of assessing model fit. Sociological Methods \& Research, 21, 230-258.

Brug, J., de Vet, E., de Nooijer, J., \& Verplanken, B. (2006). Predicting fruit consumption: Cognitions, intention, and habit. Journal of Nutrition Education and Behavior, 38, 73-81.

Cheng, S., Lam, T., \& Hsu, H. C. (2005). Testing the sufficiency of theory of planned behavior: A case of customer dissatisfaction response in restaurants. Hospitality Management, 24, 475-492.

Cong, L. C., Olsen, S. O., \& Tuu, H. H. (2012). The roles of ambivalence, preference conflict, and family identity: A study of food choice among Vietnamese consumers. Food Quality and Preference, 28(1), 92-100.

Conner, M., \& Armitage, C. J. (1998). Extending the theory of planned behavior: A review and avenues for further research. Journal of Applied Social Psychology, 28, 1429-1464.

Conner, M., \& McMillan, B. (1999). Interaction effects in theory of planned behavior: Studying cannabis use. British Journal of Social Psychology, 38, 195-222. 
Conner, M., Norman, P., \& Bell, R. (2002). The theory of planned behavior and healthy eating. Health Psychology, 21, 194-201.

Cortina, J. M., Chen, G., \& Dunlap, W. P. (2001). Testing interaction effects in LISREL: Examination and illustration of available procedures. Organizational Research Methods, 4(4), 324-360.

De Bruijn, G. J., Kremers, S. P. J., de Vet, E., de Nooijer, J., van Mechelen, W., \& Brug, J. (2007). Does habit strength moderate the intention-behaviour relationship in the theory of planned behaviour? The case of fruit consumption. Psychology and Health, 22, 899-916.

Eagly, A. H., \& Chaiken, S. (1993). The psychology of attitudes. Fort Worth, TX: Harcourt Brace Jovanovich.

Fishbein, M., \& Ajzen, I. (1975). Belief, attitude, intention, and behavior: An introduction to theory and research. Reading, MA: Addison-Wesley.

Fornell, C., \& Larcker, D. F. (1981). Evaluating structural equation models with unobservable variables and measurement error. Journal of Marketing Research, 18, 39-50.

Honkanen, P., Olsen, S. O., \& Verplanken, B. (2005). Intention to consume seafood: The importance of habit strength. Appetite, 45, 161-168.

Jaccard, J., Turrisi, R., \& Wan, C. K. (1990). Interaction effects in multiple regression. Newbury Park, CA: Sage.

Joreskog, G. K., \& Sorbom, D. (1982). Recent developments in structural equation modeling. Journal of Marketing Research, 19, 404-416.

Kenny, D., \& Judd, C. M. (1984). Estimating the nonlinear and interactive effects of latent variables. Psychological Bulletin, 96, 201-210.

Knussen, C., Yule, F., MacKenzie, J., \& Wells, M. (2004). An analysis of intentions to recycle household waste: The roles of past behavior, perceived habit, and perceived lack of facilities. Journal of Environment Psychology, 24, 237-246.

McMillan, B., \& Conner, M. (2003). Applying an extended version of theory of planned behavior to illicit drug use among students. Journal of Applied Social Psychology, 33, 1662-1683.

Norman, P., \& Conner, M. (2006). The theory of planned behavior and binge drinking: Assessing the moderating role of past behavior within the theory of planned behavior. British Journal of Health Psychology, 11, 55-70.

Norman, P., Conner, M., \& Bell, R. (2000). The theory of planned behaviour and exercise: Evidence for the moderating role of past behaviour. British Journal of Health Psychology, 5, 249-261.

Olsen, S. O. (2001). Consumer involvement in fish as family meals in Norway: An application of the expectance-value approach. Appetite, 36, 173-186.

Ouelette, J. A., \& Wood, W. (1998). Habit and intention in everyday life: The multiple processes by which past behavior predicts future behavior. Psychological Bulletin, 124, 54-74. 
Ping, R. A., Jr. (1995). A parsimonious estimating technique for interaction and quadratic latent variables. Journal of Marketing Research, 32, 336-347.

Saba, A., Vassallo, M., \& Turrini, A. (2000). The role of attitudes, intentions and habit in predicting actual consumption of fat containing foods in Italy. European Journal of Clinical Nutrition, 54, 540545.

Shepherd, R., \& Raats, M. M. (1996). Attitude and beliefs in food habits. In H. L. Meiselman \& H. J. H. Macfie (eds.), Food choice, acceptance, and consumption (pp. 346-364). London, UK: Blakie Academic \& Professional.

Trafimow, D. (2000). Habit as both a direct cause of intention to use a condom and as a moderator of the attitude-intention and subjective norm-intention relations. Psychology and Health, 15, 383-393.

Triandis, H. C. (1980). Values, attitudes, and interpersonal behavior. In H. E. Howe \& M. M. Page (eds.), Nebraska symposium on motivation (pp. 195-259). Lincoln, NE: University of Nebraska Press.

Tuu, H. H., Olsen, S. O., Thao, D. T., \& Anh, N. T. K. (2008). The role of norms in explaining attitudes, intention, and consumption of a common food (fish) in Vietnam. Appetite, 51, 546-551.

Tuu, H. H., \& Olsen, S. O. (2009). Food risk and knowledge in the satisfaction-loyalty relationship. Asia Pacific Journal of Marketing and Logistics, 21(4), 521-536.

Umeh, K., \& Patel, R. (2004). Theory of planned behaviour and ecstasy use: An analysis of moderatorinteractions. British Journal of Health Psychology, 9, 25-38.

Verbeke, W., \& Vackier, I. (2005). Individual determinants of fish consumption: Application of the theory of planned behavior. Appetite, 44, 67-82.

Verplanken, B., \& Aarts, H. (1999). Habit, attitude and planned behaviour: Is habit an empty construct or an interesting case of goal directed automaticity? European Review of Social Psychology, 10, 101134.

Verplanken, B., \& Melkevik, O. (2007). Predicting habit: The case of physical exercise. Psychology of Sport and Exercise, 9, 15-26.

Verplanken, B., \& Orbell, S. (2003). Reflections on past behaviour: A selfreport index of habitual strength. Journal of Applied Social Psychology, 33, 1313-1330.

Visser, P. S., Bizer, G. I., \& Krosnick, J. A. (2006). Exploring the latent structure of strength-related attitude attributes. Advances in Experimental Social Psychology, 38, 1-67.

Vo, H. D., \& Ly, H. T. (2014). Measuring the shadow economy in the ASEAN nations: The MIMIC approach. International Journal of Economics and Finance, 6(10), 139-148.

Wood, W., Tam, L., \& Guerrero Witt, M. (2005). Changing circumstances, disrupting habits. Journal of Personality and Social Psychology, 88, 918-933. 